\title{
Circumvention of drug resistance in cancer cells by a new fluoropyrimidine analogue
}

\author{
Sun Hee Kim ${ }^{1,3}$, Chi Dug Kang ${ }^{1}$, Byung Seon \\ Chung $^{1}$ and Jack C. Kim ${ }^{2}$ \\ 1 Department of Biochemistry, College of Medicine, Pusan National \\ University, Pusan 602-739, Korea \\ 2 College of Natural Science, Pusan National University, \\ Pusan 602-739, Korea \\ 3 To whom correspondence should be addressed \\ Accepted 20 June 1996
}

Abbreviations: 5-FU, 5-fluorouracil; 5-FUBO, 5-fluorouracil-1-yl-3-butanone; MDR, multidrug-resistant; CAT, chloramphenicol acetyltransferase

\begin{abstract}
The potentiation of antitumor drugs by their analogues is one of strategies for overcoming cellular resistance to chemotherapy. In attempts to improve the efficacy of 5-fluorouracil (5-FU) and overcome 5-FU resistance, we synthesized new 5FU derivatives and evaluated the potentiation effect on 5-FU cytotoxicity. 5-Fluorouracil-1-yl-3-butanone (5-FUBO), a newly synthesized 5-FU derivative, significantly potentiated the cytotoxic effect of 5FU, and the potentiation of 5-FU by 5-FUBO in 5-FU resistant cells was higher than in their drugsensitive parental cells. Surprisingly, it potentiated the cytotoxicities of vincristine and vinblastine. The potentiation of these drugs by 5-FUBO in mutidrugresistant (MDR) cells was more than in their drugsensitive parental cells. It was also shown that 5FUBO increased the intracellular accumulation of $\left[{ }^{3} \mathrm{H}\right]$ vincristine in P388/M cells, and this is related with increased cytotoxicity of vincristine. Northern blot analysis showed that the potentiation effect of MDR-related antitumor drugs by 5-FUBO was caused by inhibition of MDR1 gene expression. Also, 5-FUBO cytotoxicity in K562 cells was increased significantly upon transformation with cHa-ras.
\end{abstract}

Keywords: 5-fluorouracil, 5-fluorouracil-1-yl-butanone, multidrug-resistant cells, MDR1 gene, 5-FU resistance

\section{Introduction}

The fluororinated pyrimidine, 5 -fluorouracil (5-FU) is an antimetabolite that is frequently used in the treatment of gastrointestinal, breast, head, neck and genitourinary cancers (Kubota et al., 1988). 5-FU has multiple biochemical actions that may be responsible for its cytotoxicity.

Three explanations have been given for the cytotoxic action of 5-FU. One widely accepted explanation is that 5-fluoro deoxyuridine-5'-monophosphate, an active metabolite of 5-FU, inhibits thymidylate synthetase irreversibly (Houghton et al., 1986). Another explanation is that 5-FU is incorporated into RNA (Cohen et al., 1985), and disturbs gene expression (Akazawa, 1986). A third explanation is that 5-FU is incorporated into DNA (Swayer et al., 1984) and interferes with DNA metabalism (Swayer et al., 1984). However, although 5-FU is effective in some cancer patents when given alone or in combination with other agents, most clinicians report that the response rate to $5-\mathrm{FU}$ is only about 10 to $30 \%$ and remission, if achieved, is generally of short duration (Fujii et al., $1989 a, b)$. In an effort to enhance the 5-FU activation, various antitumor agents and nucleosides have been used in combination with the fluoropyrimidine (Darnouski et al., 1985; Nishiyama et al., 1988; Fujii et al., 1989a,b). Multidrug resistance (MDR) is an important problem in cancer therapy. In human cells, the MDR phenotype is thought to be primarily a consequence of the increased expression of the MDR1 gene. This encodes for a transmembrane glycoprotein of $170 \mathrm{kDa}$ (P-gp170) (Ueda et al., 1987). It was also reported that 5'-deoxy-5-fluorouridine (dFUrd) increased daunorubicin uptake in MDR cells with Pgp170 expression, and this is related with increased cytotoxicity (Van Der Heyden et al., 1994). Geng and colleagues reported that the NIH3T3 cells transformed by $\mathrm{c}-\mathrm{Ha}$-ras were more sensitive to dFUrd than their parental cells (Geng et al., 1991). In a previous study, we reported that a new 5-FU derivative, 5-fluorouracil1-yl-3-butanone (5-FUBO) showed strong antitumor activity against various cancer cell lines (Kim et al., 1994).

In the present work, we demonstrate that 5-FUBO significantly potentiated the cytotoxic effect of 5-FU and partially overcome the 5-FU resistance. We also searched for altered sensitivity of MDR cells to 5-FUBO in combination with MDR-related antitumor drug, vinblastine or vincristine. The results demonstated that the potentiation of these MDR-related drugs by 5FUBO in MDR cells was more than in drug-sensitive parental cells. 


\section{Materials and Methods}

\section{Chemicals}

5-FUBO and its derivatives were synthesized by J. C. Kim (Pusan National University, Korea) as described elsewhere (Kim et al., 1994). Acetyl-CoA was obtained from Sigma (St. Louis, MO). $\left[{ }^{14} \mathrm{C}\right]$ Chloramphenicol and $\left[\mathrm{G}-{ }^{3} \mathrm{H}\right]$ vincristine sulphate were purchased from Amersham (Arlington Heights, IL).

\section{Cells and plasmids}

Human colorectal carcinoma cell line HT29 was kindly provided by Dr. Y. S. Kim (UCSF, U.S.A.). Golden hamster embryo lung cell line GHE-L was cultured in Dulbecco's modified Eagle's medium supplemented with $10 \%$ fetal calf serum. Mouse leukemia cell line P388, mouse mammary carcinoma cell line FM3A and human leukemia cell line K562 were cultured in RPMI 1640 medium supplemented with $10 \%$ fetal calf serum. The MDR sublines of P388 and FM3A cells (P388/M and $\mathrm{FM} 3 \mathrm{~A} / \mathrm{M}$, respectively) were obtained by stepwise selection in colchicine (Kim et al., 1993). pMMTV ras $\mathrm{H}$ transfected K562 cells which overexpressed the Ha-ras was kindly donated by G. M. Cooper (Harvard Medical School, U.S.A.). The plasmid p432-CAT, which contains promoter region (970 bp Pstl fragment) of human MDR1 gene and bacterial chloramphenicol acetyltransferase (CAT) gene, was obtained from Y. Sugimoto (the Japanese Foundation of Cancer Research, Japan).

\section{Growth inhibition assay}

Cells were seeded $\left(2 \times 10^{4}\right)$ in 96 -well flat-bottom microtitration plates. After $24 \mathrm{~h}$, cell were treated for 96 $\mathrm{h}$ by antitumor agent with indicated concentration of 5 FUBO. The effect of antitumor drugs on cellular growth in the absence or the presence of 5-FUBO was determined using 3-(4,5-dimethylthiazol-2-yl)2,5diphenyl tetrazolium bromide (MTT) assay (Mosman, 1983).

\section{DNA transfection and CAT assay}

Subconfluent cultures of GHE-L cells were transfected with $10 \mu \mathrm{g}$ of $\mathrm{p} 432-\mathrm{CAT}$ according to the calcium phosphate coprecipitation method (Graham et al., 1973). In order to test the effect of 5-FUBO on p432CAT expression, 5-FUBO was added to the culture medium for the transfected cells, and CAT assay was carried out $24 \mathrm{~h}$ later. CAT assays were performed according to the method of Gorman et al. (1982).

\section{Drug accumulation assay}

The cells were plated into 24-well tissue culture dishes and allowed to grow to $90 \%$ confluency. The cells were washed with PBS and then incubated in $0.5 \mathrm{ml}$ of RPMI 1640 containing $24 \mathrm{nM}\left[{ }^{3} \mathrm{H}\right]$ vincristine $(8.45 \mathrm{Ci} / \mathrm{mmol})$ for 30,60 and $120 \mathrm{~min}$ at $37^{\circ} \mathrm{C}$. The cultures were rapidly washed three times with ice-cold PBS. Intracellular $\left[{ }^{3} \mathrm{H}\right]$ vincristine was solubilized wtih $0.3 \mathrm{ml}$ of $1 \%$ SDS in PBS and quantified by liquid scintillation counting.

\section{Northern blot analysis}

Total RNA was isolated from P388/M cells using Ultraspec $^{T M}$-II RNA isolation kit (Biotecx). Denatured RNA samples $(20 \mu \mathrm{g} /$ well) were fractionated by electrophoresis in 1\% agarose gel containing $7 \%$ formaldehyde and transferred to Hybond nylon membrane (Amersham), and hybridized for $20 \mathrm{~h}$ at $42^{\circ} \mathrm{C}$ in the same buffer containing the ${ }^{32} \mathrm{P}$-labeled MDR1 probe. After washing with $0.1 \%$ SDS and $0.1 \mathrm{x}$ SSC, the membranes were subjected to autoradiography.

\section{Results and Discussion}

The antitumor activity of 5-FUBO against drug-sensitive parental cells and their MDR sublines was compared in Table 1. 5-FUBO showed 2.8-fold higher antitumor activity in P388/M cells than in parental P388/S cells. Similarly, the antitumor activity of 5 -FUBO in FM3A/M cells was 3.3-fold higher in comparison with the parental FM3A/S cells. This result suggested that 5FUBO was more efficient against MDR cells than their drug-sensitive parental cells.

Moreover, we investigated the combination effect of antitumor drug and 5-FUBO on drug sensitivity against $\mathrm{HT}-29$ cells. The $\mathrm{IC}_{50}$ value of $5-\mathrm{FUBO}$ for the cells was about $0.5 \mu \mathrm{g} / \mathrm{ml}$, and this concentration of 5-FUBO potentiated the antitumor activities of 5-FU, vincristine and vinblastine by 5.1-, 4.0- and 3.2-fold, respectively (Table 2). It is interesting that 5-FUBO was rather effective against MDR sublines of cancer cells than their parental cells and potentiated the cytotoxicities of antitumor drugs in HT29 cells.

To investigate the combination effect of 5-FUBO and

Table 1. Effect of 5-fluorouracil-1-yl-3-butanone(5-FUBO) on growth of parental and drug resistant cancer cells. The $\mathrm{IC}_{50}$ value is defined as the concentration of the drug required to produce $50 \%$ inhibition of cell growth. Data obtained from triplicate experiments.

\begin{tabular}{lc}
\hline Cells & $\mathrm{IC}_{50}(\mu \mathrm{g} / \mathrm{ml})$ of 5-FUBO \\
\hline P388 & 0.42 \\
P388/M & 0.15 \\
FM3A & 0.54 \\
FM3A/M & 0.16 \\
\hline
\end{tabular}


Table 2. Effect of 5-FUBO on sensitivities to antitumor drugs of HT29 cells. Data were obtained from triplicate experiments. VCR, vincristine; VBL, vinblastine.

\begin{tabular}{lcccc}
\hline & & \multicolumn{2}{c}{$\mathrm{IC}_{50}(\mathrm{ng} / \mathrm{ml})$} & $\begin{array}{c}\text { Fold } \\
\text { Cells }\end{array}$ \\
\cline { 3 - 4 } & Drugs & None & $\begin{array}{c}+5-\mathrm{FUBO} \\
(0.5 \mu \mathrm{g} / \mathrm{ml})\end{array}$ & enhancement \\
\hline HT29 & $5-\mathrm{FU}$ & 360 & 70 & 5.1 \\
& VCR & 1.2 & 0.3 & 4.0 \\
& VBL & 3.2 & 1.0 & 3.2 \\
\hline
\end{tabular}

Table 3. Effect of 5-FUBO on 5-FU cytotoxicity of parental and various 5 -FU resistant FM3A cells. Data were obtained from triplicate experiments.

\begin{tabular}{|c|c|c|c|}
\hline \multirow[b]{2}{*}{ Cells } & \multicolumn{2}{|c|}{$\mathrm{IC}_{50}$ of $5-\mathrm{FU}(\mathrm{ng} / \mathrm{ml})$} & \multirow{2}{*}{$\begin{array}{c}\text { Fold } \\
\text { enhancement }\end{array}$} \\
\hline & None & $\begin{array}{c}\text { 5-FUBO } \\
(0.1 \mu \mathrm{g} / \mathrm{ml})\end{array}$ & \\
\hline FMЗA & 20 & 20 & 1.0 \\
\hline FM3A/R-1 & 35 & 15 & 2.3 \\
\hline FM3A/R-2 & 100 & 38 & 2.6 \\
\hline FM3A/R-3 & 130 & 31 & 4.2 \\
\hline FM3A/R-4 & 250 & 48 & 5.2 \\
\hline
\end{tabular}

5-FU and the possibility of overcoming 5-FU resistance by 5 -FUBO, we have isolated a series of sublines resistant to 5-FU, and the effect of 5-FUBO on sensitivity to 5-FU of parental and 5-FU-resistant FM3A cells was examined (Table 3 ). The results showed that 5-FUBO enhanced the antitumor activity of 5-FU and the potentiation ratio was increased as the higher degree of 5-FU resistance in 5-FU-resistant cells.

Also, the potentiation of antitumor agents by 5-FUBO was compared in drug-sensitive and their MDR cells (Table 4). 5-FUBO $(0.5 \mu \mathrm{g} / \mathrm{ml})$ potentiated the cytotoxicities of vincristine and vinblastine by 2 - and 1.5-fold in parental FM3A/S cells, but there was no effect in P388/S cells. By contrast, low concentration $(0.1 \mu \mathrm{g} / \mathrm{ml})$ of 5 -FUBO potentiated vincristine or vinblastine cytotoxicity more than 2-fold in FM3A/M and $\mathrm{P} 388 / \mathrm{M}$ cells. These results indicate that the potentiation of these MDR-related drugs by 5-FUBO in MDR cells was more than in drug-sensitive parental cells, and 5-FUBO can partially overcome the drug resistance.

The cellular accumulation of vincristine is often reduced in MDR cells (Matsuo et al., 1990). To assess the effect of 5-FUBO on the intracellular accumulation of $\left[{ }^{3} \mathrm{H}\right.$ ]vincristine, P388/M cells were pretreated with 5FUBO $(1 \mu \mathrm{g} / \mathrm{ml})$ for $24 \mathrm{~h}$, and accumulation of vincristine was measured at 30,60 and $120 \mathrm{~min}$ (Figure
Table 4. Effect of 5-FUBO on sensitivities to antitumor drugs of parental and multidrug-resistant cancer cells.

\begin{tabular}{lcccc}
\hline \multirow{2}{*}{ Cells } & Drugs & \multicolumn{2}{c}{$\mathrm{IC}_{50}(\mathrm{ng} / \mathrm{ml})$} & \begin{tabular}{c} 
Fold \\
\cline { 3 - 5 }
\end{tabular} \\
\cline { 3 - 5 } & & None & 5 -FUBO $(0.5 \mu \mathrm{g} / \mathrm{ml})$ & enhancement \\
\hline FM3A & VCR & 90 & 44 & 2.0 \\
& VBL & 51 & 34 & 1.5 \\
FM3A/M & VCR & 390 & $160^{\mathrm{a}}$ & 2.4 \\
& VBL & 83 & $41^{\mathrm{a}}$ & 2. \\
P388 & VCR & 24 & 24 & 1.0 \\
& VBL & 38 & 38 & 1.0 \\
P388/M & VCR & 190 & $90^{\mathrm{a}}$ & 2.1 \\
& VBL & 88 & $38^{\mathrm{a}}$ & 2.3 \\
\hline
\end{tabular}

a Cells were treated with antitumor drugs in the presence of $0.1 \mu \mathrm{g} / \mathrm{ml}$ 5-FUBO for $96 \mathrm{~h}$. Data were obtained from triplicate experiments.

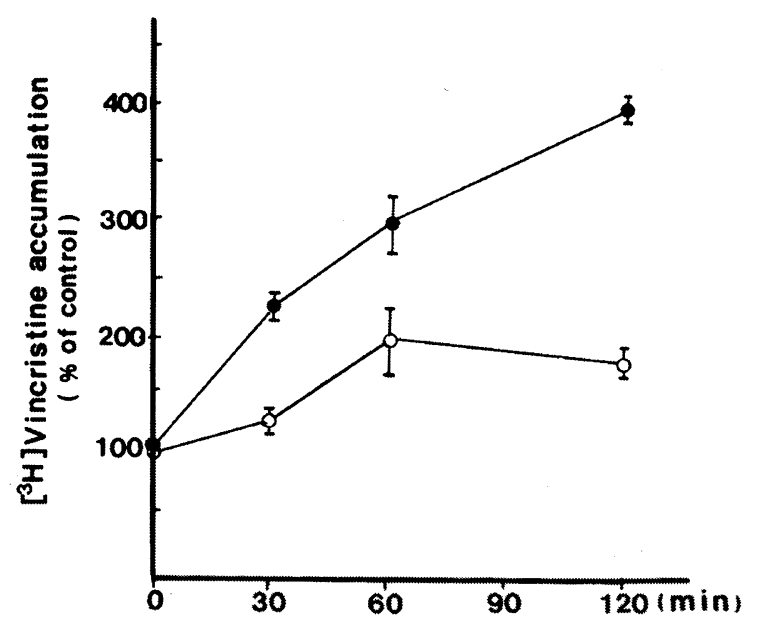

Figure 1. Effect of 5 -FUBO on $\left.{ }^{3} \mathrm{H}\right]$ vincristine accumulation in $\mathrm{P} 388 / \mathrm{M}$ cells. The cells were incubated in the absence $(O)$ or presence $(\bullet)$ of $1 \mu \mathrm{g} / \mathrm{ml} 5$-FUBO for $24 \mathrm{~h}$. [ $\left.{ }^{3} \mathrm{H}\right]$ Vincristine was then added and its intracellular accumulation after 30,60 or 120 min was detemined. Values represent the mean \pm S.D. accumulation of $\left[{ }^{3} \mathrm{H}\right]$ vincristine (solvent control $=100 \%$ ) in one of two similar experiments.

1). Pretreatment of 5-FUBO $(1 \mu \mathrm{g} / \mathrm{ml})$ caused 2 -fold increase in intracellular $\left.\left[{ }^{3} \mathrm{H}\right]\right]$ vincristine accumulation, when the cells were incubated for $120 \mathrm{~min}$ with the drug. The result shows that 5-FUBO improves the $\left[{ }^{3} \mathrm{H}\right]$ vincristine accumulation in MDR cells, and this is associated with the potentiation of VCR cytotoxicity by 5 -FUBO. Thus, we examined whether the synergistic effect of 5-FUBO with antitumor drugs was caused by inhibition of MDR1 gene expression. Northern blot analysis using MDR1 probe showed that the expression of MDR1 gene was reduced in P388/M cells by 5 -FUBO 

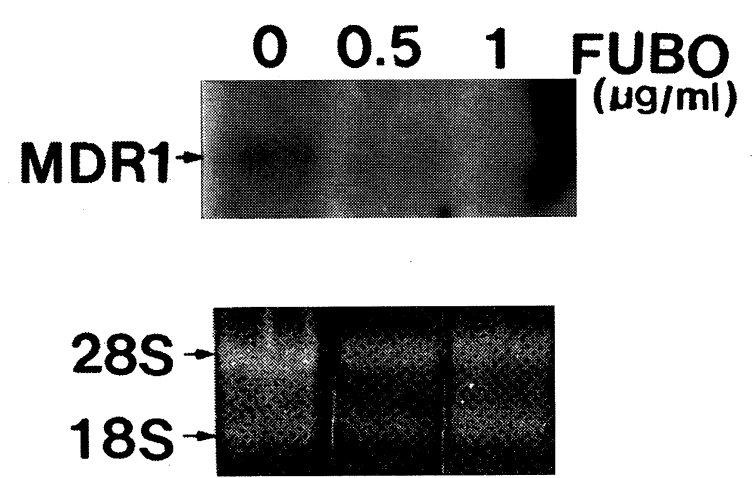

Figure 2. Effect of 5-FUBO on the expression of MDR1 gene. Total cellular RNA ( $20 \mu \mathrm{g} / \mathrm{lane}$ ) isolated from P388/M cells was resolved by electrophoresis, transfered to Hybond nylon membrane, and sequentially hybridized with ${ }^{32} \mathrm{P}$-labeled MDR1 probe.

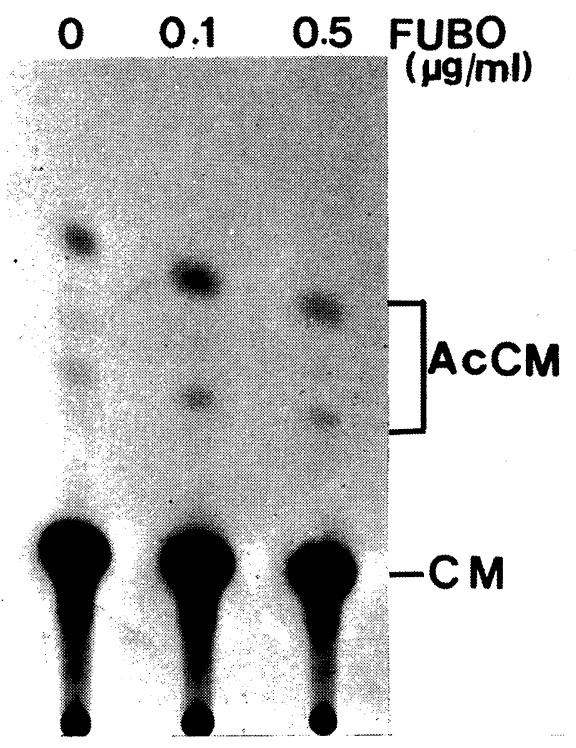

Figure 3. Effect of 5-FUBO on MDRCAT activity in GHE-L cells. The cells were transiently transfected with $10 \mu \mathrm{g}$ of p432 CAT. After $24 \mathrm{~h}$ of transfection, the cells were incubated in the presence of the indicated dose of 5 -FUBO for $24 \mathrm{~h}$ prior harvesting.

treatment (Figure 2). We also examined the effect of 5FUBO on the activity of MDR1 promotor. When p432CAT was expressed in GHE-L cells, CAT activity was reduced in GHE-L cells by 5-FUBO treatment, although the same concentrations of 5-FUBO did not inhibit cell growth (Figure 3). Two independent assays demonstrate that 5-FUBO may regulate MDR1 gene expression. Chin and colleagues reported that the promoter of the human MDR1 gene is a target for the cHa-ras oncogene product, which implies that the MDR1 gene could be activated during tumor progression associated with mutation in ras (Chin et al., 1992). It is
Table 5. Combination effect of 5-FUBO on the cytotoxicity of antitumor drugs to parenal and ras-overexpressed K562 cells. Data were obtained from triplicate experiments.

\begin{tabular}{lccc}
\hline $\begin{array}{c}\text { Antitumor } \\
\text { drugs }\end{array}$ & $\begin{array}{c}\text { Added } \\
\text { 5-FUBO }(\mu \mathrm{g} / \mathrm{ml})\end{array}$ & \multicolumn{2}{c}{ Combination effect } \\
\cline { 3 - 4 } 5 K562 & K562/ras \\
\hline \multirow{2}{*}{ F- } & 0.2 & 1.0 & 2.0 \\
VCR & 0.5 & 1.4 & 8.7 \\
VBL & 0.5 & 1.4 & 3.3 \\
ADR & 0.5 & 1.0 & 2.0 \\
\hline
\end{tabular}

of interest to explore the ras involvement in 5-FUBO activity against cancer cells. Thus, we investigated the possibility of ras involvement in 5-FUBO activation in ras-overexpressed K562 (K562/ras) cells. The 5-FUBO demonstrated the $\mathrm{IC}_{50}$ value of $1.7 \mu \mathrm{g} / \mathrm{ml}$ for $\mathrm{K} 562$ cells and of $0.6 \mu \mathrm{g} / \mathrm{ml}$ for $\mathrm{K} 562 /$ ras cells. We compared the effect 5-FUBO on drug sensitivities to 5-FU, vincristine, vinblastine and adriamycin of $\mathrm{K} 562 /$ ras cells with those of $\mathrm{K} 562$ cells. As shown in Table 5, K562/ras cells showed that the 5-FU potentiation ratio of 5-FUBO was 2- and 8.7-fold at combination dose of 0.2 and 0.5 $\mu \mathrm{g} / \mathrm{ml} 5$-FUBO, respectively, but only 1.4 -fold by combination of $0.5 \mu \mathrm{g} / \mathrm{ml} 5$-FUBO in K562 cells. 5FUBO $(0.5 \mu \mathrm{g} / \mathrm{ml})$ potentiated the cytotoxicities of vincristine, vinblastine and adriamycin by $3.3-$ to 2 -fold in K562/ras cells, but only a slight effect in K562 cells. These findings suggested that the presence of activated ras genes might help to predict response to 5FUBO.

Most antitumor drugs fail to induce clear response in the treatment of cancer. This can be explained by involvement of overexpression of the membrane glycoprotein P-gp170, which is associated with MDR and/or with involvement of ras (Chin et al., 1992).

Previous studies reported that dFUrd exerted a positive effect on daunorubicin resistance and exhibited marked cytotoxic activity in MDR cells (Van Der Heyden et al., 1994). It was also reported that dFUrd activation in NIH3T3 cells could be increased significantly upon transformation with c-Ha-ras (Geng et al., 1991). 5-FUBO itself has marked cytotoxic activity in MDR cells and ras-overexpressed K562 cells. These finding suggest that 5-FUBO seems to be useful a candidate for the treatment of MDR cells. Futher studies are necessary to explore metabolism of the drug 5-FUBO. 


\section{Acknowledgement}

This work was financially supported by a research grant (951-0709-179-1) from Korea Science and Engineering Foundation.

\section{References}

Akazawa, S., Kumai, R., Yoshida, K., Ayusawa, D., Shimizu, K. and Seono, T. (1986) The cytotoxicity of 5 -fluorouracil is due to its incorporation into RNA not its inhibition of thymidylate synthase as evidanced by the use of mouse cell mutant in thymidylate synthetase. Jpn. J. Cancer Res. 77: 602-624

Chin, K.-V., Ueda, K., Pastan, I. and Gottesman, M. M. (1992) Modulation of activity of the promoter of the human MDR1 gene by Ras and p53. Science 255: 459-462

Cohen, M. B. and Glazer, R. I. (1985) Cytotoxicity and the inhibition of ribosomal RNA processing in human colon carcinoma cells. Mol. Pharmacol. 27: 308-313

Darnowski, J. W. and Handschumacher, R. E. (1985) Tissue-specific enhancement of uridine utilization and 5-fluorouracil therapy in mice by benzylacyclouridine. Cancer Res. 45: 5364-5368

Fujii, S., Fukushima, M., Shimamoto, Y. and Shirasaka, T. (1989) Pharmacokinetic modulation of plasma 5-fluorouracil concentration to potentiate the antitumor activity of continuous venous infasion of 5fluorouracil. Jpn. J. Cancer Res. 80: 509-512

Fujii, S., Fukushima, M., Shimamoto, Y., Ohshimo, H., Imaoka, T. and Shirasaka, T. (1989) Antitumor activity of BOF-A2, a new 5-fluorouracil derivative, Jpn. J. Cancer Res. 80: 173-181

Geng, Y., Gheuens, E. E. O. and De Bruijn, E. A. (1991) Activation and cytotoxicity of 5'-deoxy-5-fluorouridine in c-Ha-ras transformed NIH3T3 cells. Biochem. Pharmacol. 41: 301-303

Gorman, C. M., Moffat, L. F. and Howard, B. H. (1982) Recombinant genomes which express chloramphenicol acetyl transferase in mammalian cells. Mol. Cell. Biol. 2: 1044-1051
Graham, F. L. and Van der Eb., A. J. (1973) A new technique for the assay of infectivity of human adenovirus 5 DNA. Virology 52: 456-467

Houghton, J. A., Weiss, K. D., William, L. G., Torrance, P. M. and Houghton, P. J. (1986) Binding of 5-fluorodeoxyuridylate to thymidylate synthase in human colon adenocarcinoma xenografts. Eur. J. Cancer Clin. Oncol. 22: 505-510

Kim, S. H., Park Y. H., Kim, D. W., Kang, C. D. and Chung, B. H. (1993) Oncogene and tumor suppressor genes regulate the human multidrug resistance gene(MDR1) expression. Mol. Cells 3: 13-16

Kim, J. C., Dong, E. S., Kim, J. A., Kim, S. H., Park J. I. and Kim, S. H. (1994) Synthesis and antitumor evaluation of acyclic 5-substituted pyrimidine nucleoside analogues. Korean J. Med. Chem. 4: 11-118

Kubota, T., Ishibiki, K. and Abe, O. (1988) The clinical usefulness of human xenografts. In Prediction of Response to Cancer Therapy (Hall, T. T., ed.), pp. 213-225, Alan R. Liss, New York

Matsuo, K., Kohno, K., Takano, H., Sato, S., Kiue, A. and Kuwano, M. (1990) Reduction of drug accumulation and DNA topoisomerase II activity in acquired teniposide-resistant human cancer KB cell lines. Cancer Res. 50: 5819-5824

Mosmann, T. (1983) Rapid colorimetric assay for cellular growth and survival; application to proliferation and cytotoxicity asay. J. Immounol. Methods 65: 55-63

Nishiyama, M., Takagami, S., Kim, R., Kiribara, Y., Saeki, T., Jinushi, K., Niimoto, M. and Hattori, T. (1988) Inhibition of thymidylate synthetase and antiproliferative effect by 1 -hexylcarbamoyl-5fluorouracil. Jpn. J. Cancer Chemother. 15: 3109-3113

Swayer, R. C., Stolfi, R. L., Martin, D. S. and Spiegelman, S. (1984) Incoporation of 5-fluorouracil into murine bone marrow DNA in vivo. Cancer Res. 44: 1847-1851

Ueda, K., Pastan, I. and Gottesman, M. M. (1987) Isolation and sequence of promoter region of the human multidrug resistance ( $\mathrm{P}$ glycoprotein) gene. J. Biol. Chem. 262: 17432-17436

Van Der Heyden, S., Gheuens, E., Van'De Vrie, W., Van Bockstaele, D., Van Dosterom, A., Eggermont, A. and De Brujjin, E. A. (1994) 5'Deoxy-5'-fluoro uridine increase daunorubicin uptake in multidrugresistant cells and its activity is related with P-gp170 expression. Jpn. J. Cancer Res. 85: 13-16 